ojs.uv.es/index.php/qdfed

Rebut: 02.06.2020. Acceptat: 07.07.2020

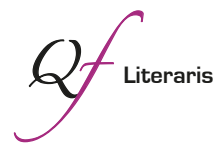

Per a citar aquest article: Méndez Rangel, Abigail. 2020. "Documental y denuncia: modelos de mundo en La libertad del diablo y Tempestad". Quaderns de Filologia: Estudis Literaris XXV: I25-I37.

doi: $10.7203 /$ qdfed.25.18993

\title{
Documental y denuncia: modelos de mundo en La libertad del diablo y Tempestad
}

Documentary film and complaint: world model in Devil's freedom and Storm

Abigail Méndez RANGel Universidad Autónoma de Puebla abghoffman@gmail.com

Resumen: El género del documental visual es uno de los medios que se han utilizado como denuncia contra los gobiernos del PRIAN en México y la desastrosa situación social a la que dio lugar. En las páginas que siguen, a la luz de la teoría de los modelos de mundo de Manuel Asensi, se ha llevado a cabo un análisis del documental de Everardo González, La libertad del diablo (20I7), y en menor medida el de Tatiana Huezo, Tempestad (20I6), cuyas premisas, silogismos y modelos de mundo están analizados a partir del montaje que nos presentan tales documentales. Los resultados ponen de relieve la capacidad modelizante de estos textos en el marco de una lucha global por la libertad y la democracia real en México.

Palabras clave: Cine documental, modelos de mundo, silogismo, afepto, violencia visual.

Abstract: The genre of visual documentary is one of the means that have been used as a complaint against de PRIAN governments in Mexico and the social disastrous situation to which it gave rise. In the following pages, taking into account Manuel Asensi's theory of world's model, we carried out an analysis of Everardo González' documentary, The Devil's Freedom, and to a lesser extent, the one of Tatiana Huezo, Storm (20I6), whose premises, syllogisms and world's models are analyzed from the films setup. The results point out the modelizing capacity of these texts within the frame of a global fight for freedom and true democracy in Mexico.

Keywords: Documentary cinema, world's model, syllogism, afept, visual violence. 
La imagen nos conduce al sentimiento (al movimiento afectivo) y éste, a la idea.

EISENSTEIN

Durante el mes de diciembre de 20I9, una noticia rodaba por los medios de comunicación mexicanos. Se trataba de un crimen cometido por un hombre perteneciente al antiguo régimen político del país, el Partido Revolucionario Institucional (PRI), cuyo crimen pulsional consistió en bañar en ácido a su ex novia, destrozándole el rostro y quemándole el 80 \% del cuerpo.

Las noticias del mes de diciembre, tres meses después de la agresión, daban a conocer los detalles: María Elena Ríos, saxofonista de la orquesta filarmónica de Oaxaca, se encuentra hospitalizada tras sufrir un ataque con ácido sulfúrico que le provocó quemaduras de tercer grado en todo el cuerpo. Se presume que el responsable es el exdiputado del PRI, Juan Antonio Vera Carrizal, quien tramitó un amparo y se ha beneficiado de su posición política para aprovecharse de la corrupción en el país, dando como resultado una impunidad en el caso. Él no ha sido enjuiciado a pesar de las pruebas que se tienen y la familia de Elena ha recibido amenazas de muerte por exigir justicia. Aún más, Elena ha tenido que vivir los estragos corruptos de las administraciones pasadas del país en las que los ministerios públicos no funcionan y en los hospitales no hay materiales de curación ni siquiera para heridas leves.

La imagen de Elena es esta (figura I), una mujer condenada a la máscara quirúrgica que, por una parte, sostenga la piel dañada y sometida a múltiples cirugías y, por otra, mantenga su rostro tapado, en anonimato. La representación de esa máscara es el símbolo de la violencia en un tiempo determinado de la historia de México, tiempo del que ya tendremos ocasión de hablar.

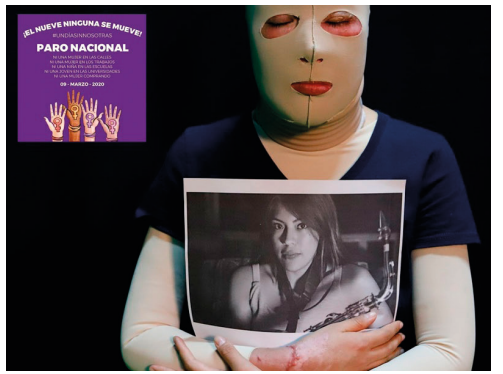

Figura I

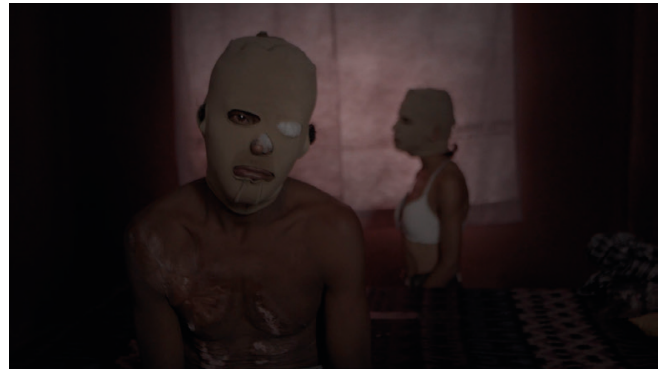

Figura 2 
En el año 20I7, dos años después de lo ocurrido con Elena Ríos, el director de cine Everardo González estrenaba su sexto documental, La libertad del diablo. Por el momento, sólo me limitaré a presentar el póster publicitario (figura 2).

Como vemos, es una imagen que presenta a un hombre que tapa su rostro con una máscara quirúrgica que, como se verá más tarde, es uno de los hilos conductores en el montaje del documental de Everardo. ¿Por qué he decidido empezar este ensayo con la mención del caso de Elena Ríos? Durante el mes en el que las noticias hablaron de la saxofonista mexicana como víctima de un ataque (cabe destacar que no es el único caso en México) con ácido, todas las imágenes, casi por obviedad, mostraban a Elena como la portadora de la máscara, como si hubiera salido del documental de Everardo González.

Si bien es cierto que en su libro publicado en 20II, Crítica y sabotaje, el concepto de reducción alegórica no está bien delimitado ni del todo desarrollado, no ocurre así en ese ensayo publicado en la revista Actio Nova (20I8) llamado “¿Qué dice la fantasía de nuestro mundo? Sobre el concepto de reducción alegórica”. A pesar de que la reducción alegórica es un procedimiento que se aplica a los textos fantásticos, también es cierto que hay una gran aportación de este concepto para todo tipo de textos: "Es el mecanismo en virtud del cual el lector o espectador refiere lo universal del modelo de mundo del texto a lo particular de su propio mundo" (Asensi, 20I8: 3I5) ${ }^{\mathrm{I}}$. De esta manera, podemos decir que la máscara en La libertad del diablo es un "accesorio" universal, es una máscara como cualquiera, una de tantas en el mundo.

Sin embargo, el concepto de reducción alegórica nos posiciona para decir que no es una máscara universal, sino una reducida a la carga de violencia como la que viven los personajes en el montaje creado por Everardo, como la que vive Elena Ríos. En definitiva, el concepto de reducción alegórica es aquel que nos abre la puerta para decir que la universalidad del objeto máscara se ve reducida a la particularidad de la carga violenta que conlleva dicha máscara.

Cualquiera a estas alturas podría pensar que la reducción alegórica es un proceso de comparación entre lo observado en un texto (en este caso un film) y algún objeto de la realidad fenoménica que te rodea. Esto es cierto hasta

\footnotetext{
${ }^{\mathrm{I}}$ Ya Asensi nos dejaba claro en ese ensayo que no es privativo de los textos fantásticos, por ello no mantendremos una discusión con dicho tema, (aunque quizá sea una aportación más de este trabajo). Ya que se trata de un film, todos estaremos de acuerdo en que es producto de un montaje, una "transformación" del mundo que da a ver de una forma determinada dicho mundo. Además, no debemos olvidar que un documental como el de González es un discurso complejo como una manifestación potencialmente performativa como el resto de discursos.
} 
cierto punto ya que una simple comparación nos reduciría a pensar que no hay más que representaciones de la realidad en los textos y que dichas representaciones funcionan solo por analogía. Si pensamos de esa manera reduccionista, corremos el riesgo de hacer caso omiso de la tradición semiótica (del Grupo $\mu$, por ejemplo), la psicoanalítica, etc. Lo importante en la reducción alegórica es precisamente la transformación que proviene del texto, la carga ideológica que lo acompaña, en definitiva el silogismo y el modelo de mundo que lo soporta.

La máscara no es un objeto fortuito que ha servido solo para mantener un anonimato en los sujetos que testimonian delante de la cámara, es un elemento que mantiene una relación estrecha, inseparable con el modelo de mundo que representa: violencia, represión, corrupción, tortura, ilegalidad, ausencia de Estado de derecho, etc. Si pensamos en la teoría del signo icónico del grupo $\mu$ (I992), diríamos que la máscara es un "objeto culturalizado" donde el referente máscara se transforma, se reduce con una carga ideológica: ya no es una máscara, es una imagen de una realidad cruenta.

Este trabajo nace de la necesidad de estudiar un film documental, La libertad del diablo (20I7) bajo la perspectiva de la teoría de los modelos de mundo de Manuel Asensi. Así, no solo se trata de poner en funcionamiento ciertos conceptos como el que ya hemos adelantado, el de reducción alegórica, sino que es mucho más: es una vuelta al pasado histórico, político y social de México; es una carta de denuncia a los procedimientos de impartición de justicia de dicho país; es un intento de aproximarse a un "género menor" como el documental; es un estudio de las formas y funciones ideológico-políticas de un documental (y algunos más que se agregan en el contexto); es un estudio del montaje y de la naturaleza semiótica que lo acompaña, de los significantes y de los espacios vacíos. Porque la teoría de los modelos de mundo no solo está para analizar los textos literarios, sino que nos permite analizar todo el campo del discurso. ${ }^{2}$ De hecho, los presupuestos que aquí se estudiarán tocan muy de cerca una realidad que se vive en México.

Es quizá esa la mayor aportación de este trabajo que presento aquí, la denuncia a partir de presupuestos que ven su riqueza teórica en el momento en el que los ponemos en funcionamiento a través del discurso. Las "aportaciones" de discusión teórica en donde se pongan en duda, en jaque, los concep-

\footnotetext{
${ }^{2}$ Se emplea la noción de "discurso" en el sentido que le dio Foucault de "la cosa escrita sancionada institucionalmente”.
} 
tos de la teoría son quizá las que menos estén presentes en este trabajo. Pero no se me olvida que es una demanda, una exigencia, un compromiso.

En el número 237 de la revista Anthropos (2012), Asensi hace una referencia si acaso corta a la reducción alegórica, diciendo que es ella la que sostiene el modelo de mundo como apelativo, incitativo y performativo: "[...] se trata de una transformación que incita a pensar, hablar o actuar de acuerdo con ese modelo de mundo. La reducción alegórica es el medio a través del cual el que el texto alcanza performativamente al sujeto" (Asensi, 20I2: 2I). Ahora diremos claramente que en el documental de Everardo González, en ese objeto alegórico que es la máscara, encontramos uno de los elementos que apelan e incitan al espectador a pensar de una forma determinada el quid de todo el documental.

Lo que resulta curioso es que las máscaras de Everardo González vienen a ser resignificadas dos años después por el suceso, tan atroz como impune, de Elena Ríos.

La libertad del diablo es un documental que ganó el festival de Berlín en el año 20I7. Tiene como hilo conductor ocho testimonios que sostienen un discurso muy marcado entre las víctimas y los victimarios, entre los buenos y los malos. Todo comienza con un prólogo, una voz en off con la pantalla completamente negra, con una musicalización poco clara producida por un sintetizador modular, que anuncia el silogismo del documental. La voz dice textualmente: "[...] veo gente enloquecida, chispas de locura, de barbarie total. No puedo pensar en esas personas como mis iguales, en esos momentos no me puedo hermanar con ellos... y sin embargo, seguimos siendo de la misma especie". Este prólogo ya ejerce sobre el documental el silogismo-modelo de mundo: la dualidad víctimas/verdugos.

Respecto a este punto hay que aclarar que, si bien se trata de una oposición jerárquica en términos derridianos, no es objeto de este ensayo hacer un análisis con las bases de la deconstrucción. Baste recordar que la teoría de los modelos de mundo no se limita a buscar las dualidades para desmontarlas y denunciarlas, sino que además parte del supuesto según el que no existiría tal binomio si un silogismo no lo soportara. Dicho de otra manera, de nada serviría denunciar un binomio de tales características (buenos/malos), si no somos capaces de desarrollar el proceso mediante el cual puede funcionar esa dualidad en la subjetividad del espectador. Es por ello que este ensayo sugiere un estudio en el que se analicen las claves por las que un binomio como el bien y el mal se inscriben en una cultura a partir de un entramado semiótico complejo como el documental. En definitiva, Derrida no termina 
de explicarnos de qué manera una oposición instaura en la subjetividad de una sociedad como un elemento potencialmente performativo; la teoría de los modelos de mundo, sí.

Dicho lo anterior, continuamos con el análisis. La imagen se abre con lo que ya se sospechaba, una imagen desoladora, desconcertante, aterradora que acompaña al ambiente nublado:

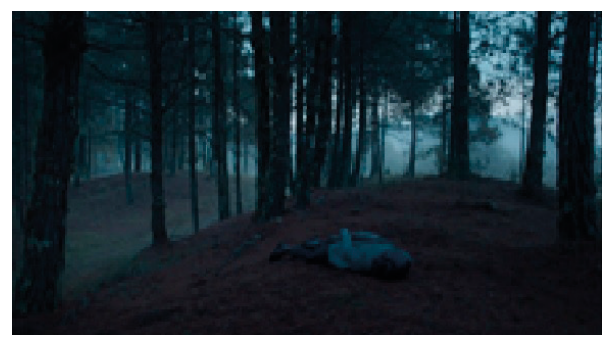

Figura 3

En plano general, donde yace un cuerpo tirado en medio del bosque, atado de brazos y piernas con una bolsa en la cabeza, muerto, abandonado. A partir de aquí todo se sostiene bajo una narrativa fragmentada que $d a$ a ver a los subalternos. El primer testimonio es de una mujer, cuya voz revela una juventud marcada. Aquí el documental va a establecer una estructura continua de presentación de personajes, testimonio y cierre de testimonio. La primera presentación corresponde a una mujer que aparece al fondo de un pasillo que obliga a mirarla por el efecto de luz que provoca. La cámara, en un plano medio la enfoca y ella mira directamente. La profundidad de campo logra efectos de dramatismo que siempre van seguidos por una transición a primerísimo plano de los rostros que tomarán la palabra. Esa imagen es importante porque aparece por primera vez la máscara que se asemeja a la de Elena Ríos con la que comenzamos este ensayo.

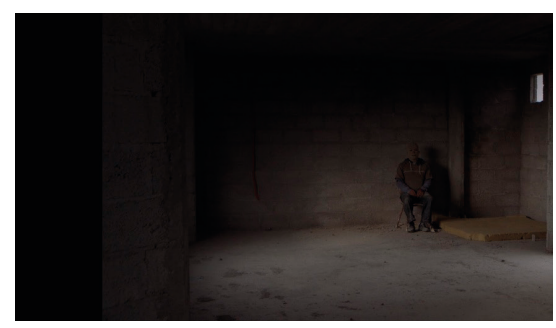

Figura 4 
Los testimonios van guiados por un entrevistador que les hace preguntas (aunque no todas se escuchan; gesto curioso) que están como una voz en off. La primera pregunta explícita en el audio es “¿Cuál fue la última imagen que recuerdas de tu mamá?”. La mujer relatará el momento en el que su madre es secuestrada por unos desconocidos y cómo el paradero de su madre es desconocido después de haber pasado varios años. Es curioso que esa pregunta soporte ya un silogismo. La premisa es clara: el silogismo se sostiene bajo una estructura de pregunta-respuesta en el que la pregunta busca claramente un tipo de respuesta y no otra. Un modelo de mundo que espera recibir una narración que conduzca a la descripción del mal.

Los personajes se quedan en un primer cuadro, casi inmóviles, rostros descompuestos por lágrimas (figura 5). Extensos planos fijos y cercanos que simbolizan un vigor en el drama por toda la película. Ese es el montaje que sostiene el silogismo.

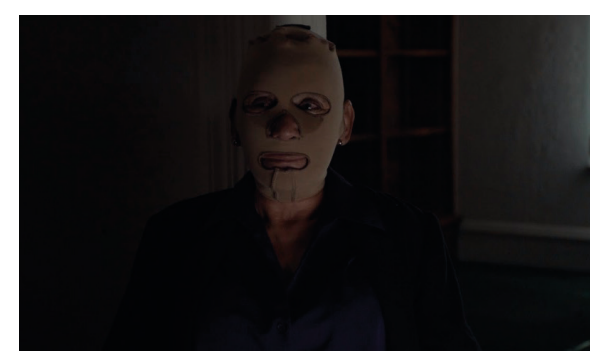

Figura 5

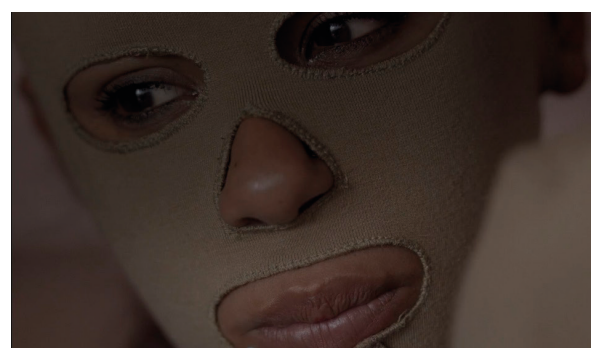

Figura 6

Es a partir de aquí que comienzan a seducir la mirada y la voz. Las voces de los personajes entrevistados no están musicalizadas. La música hace presencia antes o después de la narración, acompañando las imágenes de vida cotidiana en medios y primeros planos, pero también planos abiertos, siempre triste, lenta. Además se produce una dislocación entre el rostro y el discurso, ya que muchas veces el personaje está callado, pero oímos su voz. Es esta una manera de aislar el dolor de las víctimas.

Hemos dicho ya que uno de los soportes del silogismo es la dialéctica entre la pregunta y la respuesta. El entimema es evidente aquí porque no dejaremos de señalar que la pregunta no siempre es explícita, que los cortes de edición las suprimen en muchos casos, pero la respuesta desvela el entimema y construye al silogismo completamente. Pongamos el ejemplo de la mujer de la figura 5. Se trata de una mujer de edad avanzada que encuentra a sus dos hijos 
asesinados, enterrados en el desierto; es el primer testimonio que introduce algo más allá de la propia maldad, introduce el discurso de la corrupción, el contubernio de las autoridades con el crimen, el estado fallido, la incompetencia del ministerio público:

Yo con mi angustia de querer encontrar a mis hijos, yo quería que me ayudaran a encontrarlos. No hubo manera de que me dejaran entrar a la fiscalía porque me dijeron que no había ministerio público.

Es ese estado fallido el que obliga a las personas a hacer justica por su propia mano, a buscar por su cuenta a sus desaparecidos. Así, en ese afán por buscar a sus seres queridos, van apareciendo historias en las que las personas que buscan terminan siendo torturadas, violadas, golpeadas, secuestradas, etc.

El modelo de mundo en el que se sostiene la maldad se ve aún más marcado cuando aparecen los testimonios de los sicarios. Así es, Everardo González hace un documental en el que los dos bandos se encuentran. Es tan importante el testimonio de las víctimas como el de los sicarios. La premisa, silogismo o entimema se hace evidente con la contraparte de las víctimas. Ya habíamos adelantado que la tesis fundamental en este ensayo es que el silogismo halla su fundamento en dos aspectos. Por una parte está la evidente dialéctica entre pregunta y respuesta y, por otra, el montaje realizado por González (planos y encuadres de la cámara, música, imágenes, etc.). Es este último el que sostiene las condiciones afeptivas del film.

Un lector cuidadoso se dará cuenta de que la dialéctica entre el que pregunta y el que contesta es el entramado narrativo principal que abriga el entimema y el modelo de mundo. Pongamos algunos ejemplos:

Víctimas:

- ¿Cómo eran las personas que se llevaron a tu madre, su voz, su rostro?

-Era muy joven. Agarraba su arma muy fuerte, pero a la misma vez como con miedo. Andaba todo drogado y las voces que recuerdo eran puras malas palabras. Pero era gente normal, pues. Sientes miedo, sientes que en ese momento ya te vas a morir. Estás esperando a ver qué va a pasar.

— ¿Si los tuvieras enfrente qué harías? ¿Cómo podrías hacerles sentir miedo si pudieras? ¿Qué les daría justicia?

-Ni perdón ni olvido. Castigar a los responsables. Los mataría, los torturaría, los haría sentir miedo como mi mamá sintió. Hacerles saber que soy dueña de su vida, de su miedo, de sus sentimientos. 
— ¿Preferiría matar a alguien en lugar de entregarlo a la autoridad? ¿Cómo es el torturador, es un ciudadano común, se le mira normal? ¿Cuándo se pierde la esperanza?

Victimarios:

—¿¿Lloras en estas cosas? ¿Cuándo llega el remordimiento? ¿Serías capaz de pedir perdón? ¿Qué se siente quitarle la vida a alguien? ¿Qué te produce matar a alguien? ¿Qué te da? ¿No te dan ganas de salir corriendo? ¿También los niños suplican? ¿Qué cambió en ti la primera vez que tuviste que matar a un niño? - Mi primer muerto fue a los I4 años. Ya no se sentía nada. Te da dinero, te da poder. Los pilotos se enorgullecen por las horas de vuelo que tienen, aquí es que entre más muertos... estoy más chavo, tengo tantos muertos atrás de mí; eso como poder, nada más. Una raya más al tigre, le dicen. Mi primer coche fue a los I4 años, un Audi A4. Pediría perdón, de todo corazón, con todo mi ser.

El modelo de mundo presente en la dialéctica pregunta-respuesta se presenta de inmediato. Se trata de colocar a "los malos", los sicarios, de un lado y a las víctimas del otro. Denota un camino marcado por la premisa que es posicionar al otro como bueno o como malo. Este documental demuestra casi de forma magistral que el diablo, la maldad, están en libertad, no tiene filtros, es como cualquiera de nosotros, normal, cualquier tipo común.

El modelo de mundo de quien pregunta se hace evidente en todo momento, ejerciendo sobre la víctima o el verdugo una línea discursiva que le permita codificar la maldad y la bondad. Es "antinatural" preguntarle a un sicario si pediría perdón después de haber matado a una decena de personas a sus escasos I7 años. La intencionalidad del interlocutor asoma como aquel que toma una postura política clara: nosotros somos los buenos, ustedes los malos. La maldad no tiene rostro (por eso todos llevan la misma máscara), pero le pido a mi entrevistada que me la describa porque la dialéctica se contradice, el silogismo asoma en esa contradicción y el modelo de mundo delata al sujeto de la enunciación que lo hace hablar desde una posición política clara.

El montaje es el otro elemento que tiene efectos de fascinación afectiva y, más especialmente, afeptiva. Como bien lo demuestra Asensi en su texto sobre Gus Van Sant (2013), es necesario analizar la materialidad semiótica en los filmes, y en los discursos en general, porque es ahí, en el montaje, donde se ubica su poder performativo. El director apela a los sentimientos del espectador quien (con la anamorfosis que sufren las máscaras por las lágrimas del portador o portadora, por ejemplo), potencialmente, tomará una posición que 
lo incitará a actuar de una manera u otra, tomando una posición apelativa y performativa que seguirá o rechazará.

Se está de un lado o de otro, según las premisas de la película, según los conceptos que ella soporta. De ahí el concepto Afeptivo:

"El hecho del que el concepto, el percepto y el afecto no puedan separarse en la obra literaria, viene de hecho a subrayar que la efectividad del silogismo entimemático presente en un texto se ve reforzada y ampliada por su dimensión afectiva [...] toda forma específica de las diferentes artes y textualidades, supone una diferente manera de amalgamar lo conceptual y lo afectivo" (Asensi, 20II: 46).

En La libertad del diablo, la cámara siempre está fija, no tiene movimiento, sino que apela al movimiento "natural" del paisaje. En ese sentido parece una naturaleza muerta. El estatismo de la cámara, la inmovilidad absoluta de la cámara sistemáticamente colocada, mantiene un marco estable que provoca una tensión interna. El movimiento afeptivo que realiza González es análogo al de Tatiana Huezo en su documental Tempestad (2016), donde se denuncian dos casos de violencia mediante la voz en off de dos mujeres con historias distintas pero igualmente terribles. La primera sufre un encarcelamiento sin razones aparentes, simplemente porque "le toca" a ella como a quien le toca la lotería. El documental de Tatiana, del mismo modo que el de Everardo, comienza con una pantalla negra en la que se escucha la voz de una mujer: "Todas las mujeres estaban dormidas, era de madrugada porque la cárcel estaba ya en silencio [...] pensé que venían por mí para llevarme a la celda de castigo". Como vemos, ya desde el primer momento el silogismo aparece en esas palabras con una angustia y un miedo evidente. El espacio se configura como triste, envolvente en un estado de prisión.

Se abre entonces la primera imagen, una casa abandonada, derruida, mientras el discurso de la mujer, Miriam Carbajal, narra el momento en el que es puesta en "libertad". Las ventanas de la casa en cuestión son puestas en primer plano por la cámara haciendo una sinécdoque que simboliza la destrucción de la mujer. Inmediatamente después, la mujer, el sujeto de la enunciación, nos ubica en el tiempo y espacio del montaje documental: "Sabíamos que en Matamoros había un toque de queda. La ciudad estaba como en guerra. Había enfrentamientos todos los días entre los Zetas y el cártel del Golfo y la policía”. El espacio ya asoma el modelo de mundo: la vida cotidiana en un espacio en conflicto de violencia total. No es fortuita la imagen (las imágenes comulgan con el espacio en conflicto) en la que vemos una calle cualquiera en 
la que aparece una cruz en el suelo que es un gesto "tradicional" en México que se usa cuando una persona muere en la vía pública. (Figura 9)

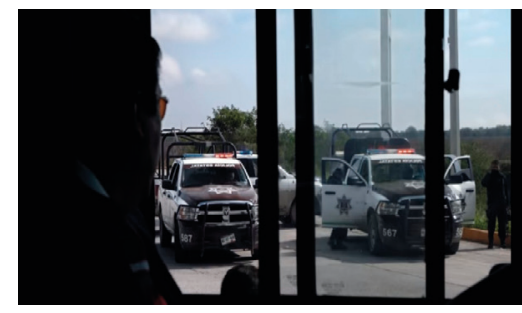

Figura 7

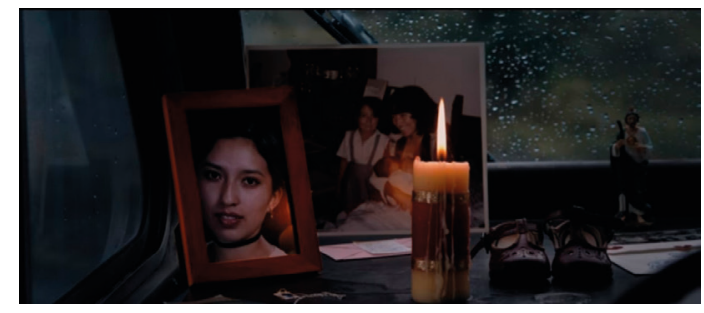

Figura 8

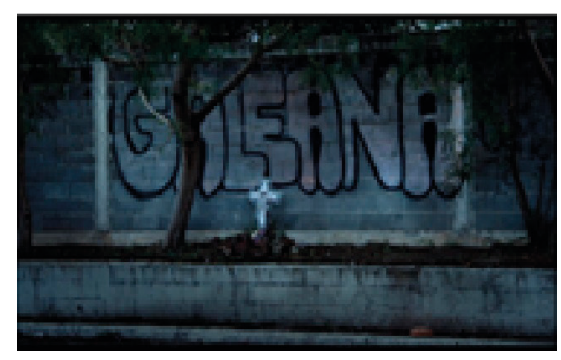

Figura 9

A partir de ahí, las imágenes y la narración se construyen como un oxímoron en el que la contradicción genera un efecto, por una parte, de la voz que cuenta el recuerdo de lo vivido en la cárcel desde que la detuvieron, hasta que sale y, por otra, las imágenes que son un símil del camino que va de Tamaulipas a Tulum (la cárcel-casa), 2000 kilómetros de viaje. Un símil porque no son "reales", sino un montaje que la directora utiliza para acompañar los recuerdos de Miriam. Cabe resaltar que las imágenes no son una dramatización del discurso, sino una metáfora, una alegoría del escape de una mujer que lo único que quiere es largarse de todo aquello que la mantuvo encerrada tres meses.

Las imágenes dan a ver de inmediato un modelo de mundo en el que la utilización de las armas en el espacio público es habitual y en el que la militarización de la ciudad es evidente. La segunda historia que se cuenta es la de una madre desesperada por encontrar a su hija, quien fue secuestrada por la policía, entregada por un compañero de clase de la joven estudiante. La familia, la madre, sospechan que fue "levantada" por los judiciales para 
entregarla al crimen organizado de trata de personas y prostitución (por cierto, es el supuesto crimen por el cual culpan a Miriam). Después de io años, Mónica, la chica desaparecida sigue sin aparecer. El final del documental es absolutamente distópico, el silogismo, pues, es el que contiene la premisa: ni dentro ni fuera estás a salvo, la violencia está en el espacio común. Miriam dice "Cuando salga de aquí iré al mar todos los días con mi hijo". Cuando sale de la cárcel y llega a su casa, lo único que le ocurre es que tiene miedo, no puede salir ni a la esquina. Está claro, ni hay playa todos los días, ni aparece la joven después de diez años de búsqueda incansable.

Ambos documentales plantean un modelo de mundo de tristeza, abandono, barbarie, desigualdad, estado fallido, ausencia del estado de derecho, corrupción: vivir en México significa estar en peligro de morir todos los días. Modelo de mundo donde se desconoce la autoridad como portadora de la ley justa. Son los representantes del gobierno, la policía, el ejército, la presidencia en turno, etc. los encargados de corromper, arruinar la vida de las personas: "ellos, los judiciales, sabían que esa cárcel estaba controlada por el narcotráfico. Ellos me entregaron al crimen organizado", dice Miriam. "La policía, la AFI, no nos dejó buscar, nos retuvo en casa por seis meses fingiendo buscar a mi hija. Ahora nos tienen amenazados de muerte, vivimos escondidos, pero no tengo miedo", dice la madre de Mónica.

"Si le rascamos a la historia, en donde está postrado el cuartel del Ciudad Juárez, el cuartel militar, de ahí sacaron muchas osamentas. Inclusive del propio cuartel militar. Eso era un cementerio. O sea que ahí mismo enterraban a las personas que secuestraban, que levantaban por una orden... si quieres dinero, pasarla bien, te tienes que involucrar demasiado, tienes que hacer lo que te dicen, somos especialistas en cumplir órdenes. Ya elegí mi lado, ver la corrupción. La vida en Ciudad Juárez vale 200 pesos. Matar a alguien cuesta eso. ¿Quieres vivir? Tienes que ir con la corriente", dice un militar en La libertad del diablo.

No puedo cerrar este ensayo sin antes decir que jamás se ha pretendido restarle mérito al carácter de denuncia de los documentales, sino todo lo contrario, es el carácter de denuncia, de trabajo exhaustivo de documentación de los directores, lo que ha desencadenado la necesidad de estudio. A la vez es la teoría de Asensi la que ha participado en el análisis, porque qué duda cabe de que también es una teoría política, de compromiso social.

No podemos olvidar tampoco que los documentales denuncian y repudian un evidente estado fallido que comenzó a construirse con el imperio del partido que dominó durante más de 7 décadas en México, el PRI y el PAN (conoci- 
do como el PRIAN). Los muertos que llevan en sus espaldas a partir del pacto con el crimen organizado ${ }^{3}$ ¿quién podría ignorarlos? Solo aquellas personas cuya consciencia social sea nula, cuyos intereses estén respaldados por un gobierno autoritario y corrupto. El futuro del país ahora se ve en un panorama más justo que espera reivindicar todo el daño que hicieron sus antecesores. Se espera del gobierno actual, por fin democrático, que resuelva en la medida de lo posible todos los casos, los innumerables casos de violencia y ultrajo que nos han heredado.

\section{Bibliografía}

Asensi Pérez, Manuel. 20II. Crítica y sabotaje. Barcelona: Siglo XXI/Anthropos.

Asensi Pérez, Manuel. 20I2. Modelos de mundo y lectores/as desobedientes. Cuadernos de cultura crítica y conocimiento 237: 17-30.

Asensi Pérez, Manuel. 2013. Elefantes en el ojo de gus van sant (los modelos de mundo en elephant). Archivos de la filmoteca, cine e hibridaciones: avatares de la era digital 72: XLVII-LXII.

Asensi Pérez, Manuel. 20ı8. ¿Qué dice la fantasía de nuestro mundo? Sobre el concepto de "reducción alegórica". ACTIO NOVA: Revista de Teoría de la Literatura Y Literatura Comparada 2: 310-330.

Foucault, Michel. I999. El orden del discurso. Barcelona. Tusquets.

Freund, Gisele. I993. La fotografía como documento social. Barcelona: Gustavo Gili.

Grupo 1. I992. Tratado del signo visual. Madrid: Cátedra.

González, Everardo (dir.). 20I7. La libertad del diablo. [DVD]. México: Animal de luz films.

Huezo, Tatiana (dir.). 2or6. Tempestad. [DVD]. México: Pimienta films.

Martin, Marcel. 2002. El lenguaje del cine. Barcelona: Gedisa.

\footnotetext{
3 Disfrazado de "lucha contra el crimen". Ese sí que fue un montaje en el sentido de ficción absoluta, cobijada por los medios de comunicación evidentemente vendidos al sistema del momento, cuyas notas periodísticas se prestaron a la mentira, a la supuesta batalla en contra del narcotráfico que jamás se llevó a cabo. De hecho, este es tema para otro ensayo: modelos de mundo en los medios de comunicación, arropando al estado fallido en México.
} 
